\title{
O IMPACTO DA REFORMA TRABALHISTA EM GESTANTES
}

\author{
Barbara Maria de Oliveira Vilella, Marcos Vinicius da Silva, Thainá Arcanjo da C. Silva \\ Universidade do Oeste Paulista - UNOESTE, curso de Direito, Presidente Prudente, SP. E-mail: barbara- \\ vilella@hotmail.com
}

\section{RESUMO}

O presente artigo tem por objetivo analisar um dos pontos da reforma trabalhista, onde o foco permanece sobre a mulher grávida e o trabalho laboral em locais insalubres. Ao longo dos anos vem se discutindo a função da mulher no trabalho e as condições em que são expostas durante o período de gestação. Com a reforma trabalhista, estabeleceu-se mudanças nesse cenário com a introdução de mulheres ao trabalho insalubre quando o grau é mínimo ou médio, o que antes era de total proibição pela lei. O intuito principal da reforma é a abertura de novos empregos e a melhora da economia, porém isto pode acarretar mudanças drásticas.

Palavras-chave: Reforma, Gestantes, Insalubridade, Mudanças, Trabalho.

THE IMPACT OF THE LABOR REFORM ON PREGNANT WOMEN

\section{ABSTRACT}

This article aims to analyse one of the points of labor reform, where the focus remains on the pregnant woman and labor in unsanitary locations. Over the course of the women's role in the work and as conditions in which they are exposed during the gestation period. With labour reform, there were changes in this scenario with the introduction of women to unhealthy work when the degree is minimal or medium, which was a total ban by law. The main intention of the reform is an opening of new jobs and an improvement in the economy, but it can involve drastic changes.

Keywords: Reform, pregnant women, unhealthy, changes, work

\section{INTRODUÇÃO}

Muito se tem discutido, recentemente, acerca da nova reforma Trabalhista, aprovada pelo Senado e sancionada pelo Presidente, sobre os impactos que poderiam causar sobre a sociedade e o dia a dia do trabalhador. Pontos que recebem importante atenção e cuidado ao serem analisados. Apesar da discussão pública, está reforma é defendida pelo governo visando uma forma de melhorar estimular a economia, criando também novos empregos.

Destaca-se nesse artigo, assunto relevante sobre a situação de mulheres gestantes em trabalhos insalubres, pois com a reforma trabalhista, é previsto a possibilidade de grávidas trabalharem em condições que podem fazer algum mal à sua saúde, como radiação em excesso ou frio, mas desde que esta insalubridade não seja em seu grau máximo. Nesses casos, a grávida será transferida para outra função.

Antes, algo que não admitia-se sob nenhuma hipótese, torna-se possível com esta reforma, permitindo o afastamento apenas sob atestado médico.

Dentro deste tema especifico, outro ponto mudado pela reforma, encontra-se também sobre a amamentação, onde as mulheres poderão trabalhar em locais insalubres, independente do grau. Fato que não era permitido até antes da reforma.

A reforma trabalhista entrará em vigor a partir de Novembro deste mesmo ano, podendo ainda sofrer mudanças em seu texto legal. 
O objetivo deste estudo foi abordar este tema mais afundo e quais os possíveis problemas que poderão sofrer as mulheres diante da reforma proposta.

\section{METODOLOGIA}

Para o desenvolvimento deste trabalho se fez necessário examinar a Lei 13.287/2016 sancionada pela Ex-Presidente Dilma Rousseff, a qual proíbe o trabalho de gestantes e lactantes em atividades, operações ou locais insalubres, constatando-se que a mesma foi criada no intuito de proteger a gestante e o nascituro, preservando assim a saúde de ambos. No entanto, esta medida apesar de ter como intuito ser protetiva para as mulheres, teve um trecho vetado, o qual garantia a manutenção do adicional de insalubridade, além do pagamento integral do salário.

Isto porque o mesmo foi considerado prejudicial as mulheres devido ao período de lactação, pois se assim fosse, após o termino da estabilidade da gravidez, o empregador poderia vir a demiti-la. E até mesmo passarem a contratar mais profissionais do sexo masculino, pois os mesmos não estarão amparados por este dispositivo de lei, limitando assim a atuação das mulheres no âmbito do mercado de trabalho.

O relator da proposta, o senador Marcelo Crivella (PRB-RJ), em seu relatório, defendeu a continuidade do pagamento adicional, afirmando: "o comprometimento da renda da trabalhadora poderia fazer com que ela buscasse formas de evitar tal afastamento, ainda que expondo a risco sua saúde e a de seu bebê".

Já Vólia Bomfim Cassar, argumenta a respeito da nova lei apenas fazendo menção a ausência da inclusão do nascituro em seu dispositivo, e declarando que "apesar de perigosa, pois há profissionais irresponsáveis, não vemos problema na proposta que autoriza o trabalho da grávida em local insalubre desde que concedida por médico que declare que o trabalho não prejudique sua saúde nem a do bebê".

Art. 394-A. A empregada gestante ou lactante somente poderá trabalhar em ambiente insalubre mediante a apresentação de atestado médico que comprove que o ambiente não afetará a saúde ou oferecerá algum risco à gestação ou à lactação.

\section{RESULTADOS}

Com relação ao tema arguido acima, expõe-se agora jurisprudências a fim de comprovar o estudo feito acerca do tema, no que tange dispensa imotivada de gestantes, e a justificativa de seus reconhecimentos.

\section{RECURSO ORDINÁRIO. DISPENSA IMOTIVADA. EMPREGADA GESTANTE. ESTABILIDADE PROVISÓRIA. RECONHECIMENTO.}

A disposição contida na alínea $b$, inciso II, art. 10 do ADCT da atual Constituição Federal tem como fim a proteção da proteger a mulher grávida da dispensa imotivada. $O$ referido dispositivo legal é expresso ao vedar a dispensa arbitrária ou sem justa causa de empregada gestante, desde a confirmação da gravidez até cinco meses após o parto, sendo, portanto, o empregador responsável pelos salários e demais direitos decorrentes do contrato de trabalho durante o período de estabilidade. Cumpre destacar, ainda, que o fator essencial ao direito à estabilidade consiste na prova de que o início da gravidez ocorreu durante a constância da relação contratual, de modo que a responsabilidade do empregador, neste caso, é objetiva, consoante o entendimento consubstanciado na Súmula 244 da C. TST. Recurso da reclamante a que se dá provimento. (TRT 1, 2016).

A jurisprudência acima é um de vários exemplos do que irá continuar acontecendo, independente de nova mudança de lei. Pois mesmo se o médico atestar que o local é de mínima 
ou média insalubridade, poderão acarretar danos à saúde da mulher assim como o do bebê. Em relação as demissões injustificadas, a mulher tem por lei, a partir do momento em que se tem o conhecimento de sua gravidez, a licença maternidade garantida. Seria de extremo erro demiti-la após eu retorno quando se trata de um direito já garantido pela própria constituição federal, levando questionamento sobre a inconstitucionalidade de tal artigo de lei.

\section{DISCUSSÃO}

É de conhecimento geral, em nosso país, há tempos, a vontade de criar reformas em leis e institutos, buscando assim auferir uma base aliada para ser colocado em prática. Para realizar medidas em um país que anda querendo entrar em uma recessão e um déficit na economia, tentando alavancar a economia e o crescimento de vagas de empregos, que em um pais de mais de 190 milhões de Habitantes, e está numa fase não muito favorável por culpa dos escândalos políticos, dos mensalão, já em outros Países estamos sendo mal visto por não ser um País confiável para investimento e com isso a taxa de desemprego vem aumentando, segundo a fonte do IBGE no mesmo bimestre do ano passado de 2016 eram apenas 5 milhões de desempregados, onde hoje no mesmo bimestre deste ano de 2017 já se ultrapassa os 24 milhões de desempregados um percentual de $31 \%$ a mais do que 5 anos atrás onde a maior taxa de desemprego foi $12 \%$ no ano de 2012 , isso tendo em base da pesquisa sobre o ano de 2016 e no mês de janeiro desse mesmo ano de 2017, ( Fonte: IBGE),

Tendo um País em um desordem, uma economia em queda, a troca de governos, a falta de credibilidade diante do comercio internacional, fez com que a vontade de fazer as reformas políticas se tornassem necessárias e urgentes.

Para um governo Não muito aceito pela População brasileira, O chefe do Poder executivo faz uma verdadeira troca de barganhas, em trocas de cargos e favores entres os Deputados e senadores para que esses votem a favor das mudanças, e em suas Pautas de extrema urgência está a reforma trabalhista e a reforma Previdenciária ambas no ponto de vista necessárias.

Com a reforma trabalhista aprovada pelo congresso nacional no dia 11/07/2016 e que entrará em vigor no mês de novembro deste mesmo ano de 2017 muitas coisas vão mudar, como por exemplo a terceirização da atividade meio e fim e sua regulamentação, o acordo de demissão entre patrão e funcionário que antes não podia, era uma fraude, que nesse novo texto permite, horas extras e entre outras inovações. Porem na pesquisa em estudo vamos ver a questão para as gestantes e lactantes que teve também mudanças.

Vamos começar do Ponto de partida de uma gestante que trabalha que é a licença maternidade:

Sendo um direito constitucional e sendo vetada a alteração desse dispositivo constitucional, as mulheres contratadas pela CLT continuam com os seus 120 dias de licença sem alteração, e as trabalhadoras gestantes que pertencem ao grupo de empresas cidadãs, a licença pode ser estendidas por mais 60 dias somando um total de 180 dias.

O intervalo para amamentação do bebe de 30 minutos por 2 vezes ao dia até completar os 6 meses conforme a CLT Art. 396, teve uma pequena alteração somente no tempo, esse tempo de 30 minutos terá que ser negociado com o empregador.

Aviso de demissão: A trabalhadora não tinha tempo para informar sua gestação ao empregador após ser demitida, com a nova redação a trabalhadora gestante tem até 30 dias após a demissão para informar sua gestação ao empregador.

Insalubridade: Antes A gestante não poderia de forma alguma trabalhar em lugares insalubres, nem de grau baixo, médio ou alto, porem um novo dispositivo presente nessa reforma permite que a trabalhadora trabalhe em lugares insalubres, desde que seja de nível baixo ou médio. Porem para a empresa se valer desse dispositivo terá que ter em mão o atestado médico 
atestando que a gestante possa trabalhar naquele ambiente insalubre de baixa e media intensidade, sendo vetado que em hipótese alguma a gestante possa trabalhar em local de salubridade elevada, tendo esta ter que ser remanejada se setor, ou função.

Férias : De acordo com a Nova legislação, as férias é um direito do trabalhador, porem veio com uma alteração sendo que o empregador poderá dividir as férias em 3 partes, não podendo a primeira parte ser inferior a 14 dias e as demais partes não sendo inferior a 5 dias, tendo a Gestante ou mãe a preferência sempre que possível gozar das férias, durante a época das férias escolares.

Carga Horária : A regra atual é de que o trabalhador faça 8 horas diárias, concluído ao todo 44 horas semanais. Com o texto da reforma, o empregador e trabalhador, mediante acordo, poderão optar por meio do contrato individual de trabalho ou de norma coletiva a realização de trabalho diário de 12 horas por dia de trabalhadas por 36 horas/dias de descanso, conforme já ocorre em determinadas profissões tais como de médicos, bombeiros, etc.

\section{CONCLUSÃO}

Mediante o exposto, objetiva-se que a reforma sancionada trouxe determinada polêmica, e portanto se faz necessário acompanhar atenciosa e minuciosamente todos os processos que decorrerão devido à nova medida, para que seja garantido seu cumprimento como rege a lei. Pois como exposto no trabalho, trata-se de vidas.

Em virtude dos fatos mencionados, é-se levado a acreditar que o legislador ao criar a lei, em especial a parte que diz respeito às gestantes, não levou em consideração todos os aspectos e diferentes tipos de empregos existentes.

Dessa forma, entende-se que o texto legal visou a melhoria de situações para os empregadores, não ponderando a situação de trabalhadores, no caso em questão, gestantes, e os riscos que estes estarão submetendo-os. É de se analisar a motivação por trás de tal reforma, onde em contraoposição a este ideal lançado, há pessoas lutando para que o quadro seja revertido em favor das mulheres não apenas gestantes como também lactantes.

\section{REFERÊNCIAS}

Estabilidade da gestante. Disponível em:

https://www.jusbrasil.com.br/jurisprudencia/busca?q=Estabilidade+da+Gestante. Acesso em : ( $12 / 08 / 2017$ às 17 horas )

Indenização por despedida de gestante. Disponível em:https://www.jusbrasil.com.br/jurisprudencia/busca?q=INDENIZAÇAO+POR+DESPEDIDA+DE+G ESTANTE . Acesso em : (12/08/2017 às 13h30)

Reintegração. Dispensa imotivada. Empregada gestante. Recurso Ordinário da reclamante. TRT-2 RO: 1334200431402009 SP 01334-2004-314-02-00-9. Disponível em:

https://trt-2.jusbrasil.com.br/jurisprudencia/15860842/recurso-ordinario-ro-1334200431402009sp-01334-2004-314-02-00-9 . Acesso em: (05/08/2017 às 20horas)

Lei proíbe trabalho de gestante e lactante em local insalubre. Disponível em: https://martinslisboa.jusbrasil.com.br/noticias/336941716/lei-proibe-trabalho-de-gestantes-elactantes-em-locais-insalubres . Acesso em : (05/08/2017 às 19horas ) 
Reforma Trabalhista - Vólia Bomfim. Disponível em : http://www.Ifg.com.br/conteudos/artigos/geral/reforma-trabalhista-volia-bomfim-explica-osdetalhes-da-proposta Acesso em : (05/08/2017 às 20horas )

Gravidez: Quais são os Direitos Trabalhistas da Gestante?. Disponível em : http://direitosbrasil.com/direitos-trabalhistas-da-gestante/ Acesso em : ( 04/08/2017 às 14h30 )

Reforma erra ao permitir atuação de grávida e lactante em local insalubre. Disponível em : http://www.conjur.com.br/2017-jul-21/reflexoes-trabalhistas-reforma-erra-permitir-gravidalactante-local-insalubre Acesso em: ( 04/08/2017 às 15horas )

Reforma Trabalhista: o que muda para gestantes e para as mães. Disponível em: http://www.maesdepeito.com.br/reforma-trabalhista-o-que-muda-para-gestantes-e-para-asmaes/

Acesso em ( 04/08/2017 às 15h30 ) 